\title{
Cosméticos Sustentáveis e a Intenção de Compra de Consumidores no Brasil
}

\author{
Sustainable Cosmetics and the Purchase Intention of Brazilian \\ Consumers
}

\author{
Beatriz dos Anjos Furtado ${ }^{12}$
}

\begin{abstract}
Resumo
Esse artigo tem como objetivo identificar os principais aspectos que os brasileiros consideram ao comprar cosméticos sustentáveis. Os cosméticos sustentáveis englobam produtos de beleza, perfumaria e higiene com preocupação sobre a formulação, saúde, descarte, o meio ambiente e a vertente social. Esse setor é um dos mais rentáveis do Brasil, destacandose como o quarto maior do mundo. Os cosméticos sustentáveis têm diretrizes que devem estar em conformidade com o Instituto Biodinâmico de Certificações; apresentam-se dentre as especificações componentes naturais, orgânicos e livre de matérias-primas não renováveis. Considerando-se a revisão da literatura, gerou-se um modelo explicativo de quais aspectos são influenciadores nos consumidores que baseou o questionário aplicado. Foram coletadas 529 respostas com questões abertas no Brasil. Após a análise da frequência, foi verificado que certos aspectos respondem ao modelo proposto que contém as dimensões "Atitude de consumo ambiental", "Bem-estar", "Saúde", "Grupos de Referência" e "Atributos percebidos" como preponderantes. Dentre os resultados obtidos, os aspectos qualidade, saúde, meio ambiente, preço, embalagem e teste em animais preponderaram como principais intenções de compra. Tais aspectos correspondem aos fatores internos e externos que guiam ao comportamento de compra. Esses achados podem auxiliar a despertar mais estudos sobre o setor cosmético na área de sustentabilidade na academia, podendo as organizações desenvolverem novos produtos e estratégias de marketing para esse segmento.

Palavras-Chave: Cosméticos sustentáveis. Comportamento de consumo. Intenção de compra.
\end{abstract}

\begin{abstract}
This paper aims to identify the main aspects that Brazilians consider when purchasing sustainable cosmetics. Sustainable cosmetics encompass beauty, perfumery and hygiene products with concern for formulation, health, disposal, environment and social aspects. This sector is one of the most profitable in Brazil, standing out as the fourth largest in the world.
\end{abstract}

\footnotetext{
1 Universidade Federal de Juiz de Fora, Brasil. ORCID:

https://orcid.org/0000-0001-9663-8137 E-mail: beatriz.anfurtado@gmail.com
}

2 Agradecimento à CAPES pela bolsa cedida para pesquisa. 
Sustainable cosmetics have guidelines to be followed accordance with the Biodynamic Certification Institute. They are present among the natural, organic and free from non-renewable raw materials component specifications, According to the reference, an explanatory model on which aspects are consumer influencers was generated and the applied questionnaire was based on it. 529 responses with open questions were collected in Brazil. After the frequency analysis, it was verified that certain aspects respond to the proposed model that contains the dimensions "Attitude of environmental consumption", "Well-being", "Health", "Reference groups" and "Perceived attributes" as preponderant. Among the results, the quality, health, environment, price, packaging and testing on animals aspects predominated as main purchase intentions. Such aspects correspond to internal and external factors that lead to the purchase behavior. These findings may help to awaken more studies on the cosmetics sector in the area of sustainability in academia, and organizations could develop new products and marketing strategies for this segment.

Keywords: Sustainable cosmetics. Consumer behavior. Purchase intention.

$$
* * *
$$

\section{Introdução}

Os produtos enquanto bens tangíveis possuem componentes e substâncias que compõem a sua estrutura. O conhecimento sobre os componentes dos produtos, em especial aqueles considerados cosméticos, tem despertado interesse do mercado consumidor. $\mathrm{O}$ interesse dos consumidores em informações acerca da nocividade ou da capacidade dos cosméticos serem prejudiciais à saúde humana, mostra-se cada vez mais elevado no decorrer dos anos (Tozzo, Bertoncello, \& Bender, 2012; Zenone \& Dias, 2015).

A preocupação com os cosméticos, tendo em vista, além da saúde, a questão ambiental, fez surgir outros questionamentos na sociedade. Além da preocupação com o ambiente, a vertente social da produção também emerge. Nos cenários de 1972 e 1987, na Conferência das Nações Unidas e no Relatório Brundtland, respectivamente, o termo desenvolvimento sustentável é cunhado, atentando-se para o desenvolvimento econômico preocupado com a qualidade de vida para as gerações atuais e futuras (Dias, 2015; Zenone \& Dias, 2015). 
A discussão sobre desenvolvimento sustentável tem como pauta, também, o consumo sustentável, que visa promover melhorias no aspecto de consumo. Esse consumo leva em consideração produtos ecologicamente corretos e comportamento de consumidores compromissados com a sustentabilidade (Gollo, Silva, Locatelli, \& Rangel, 2015). A sustentabilidade, segundo Elkington (2004), é um termo que complementa o consumo sustentável, visto que deve haver a manutenção da qualidade das vertentes econômica, social e ambiental.

Com o consumo sustentável popularizando-se, um maior número de consumidores começa a reparar em produtos com viés sustentável, mesmo que ainda de forma tímida (Gollo, Silva, Locatelli, \& Rangel, 2015). Nas organizações, a solução para as demandas dos stakeholders é inovar e tentar satisfazer as necessidades dos clientes. Dentre os setores mais rentáveis do Brasil, o cosmético se destaca como o quarto maior do mundo. Cerca de $R \$$ 102,3 bilhões ao ano são movidos em artigos de higiene, beleza e perfumaria (Associação Brasileira da Indústria de Higiene Pessoal, Perfumaria e Cosméticos, ABIHPEC, 2019).

No caso do setor de cosméticos, a demanda sobre sustentabilidade é notória. As organizações com foco na sustentabilidade têm tentado se abster do uso de substâncias derivadas do petróleo, investindo mais em insumos naturais, com maior apelo sustentável (Ladeira, Santini, \& Araújo, 2015). Um novo produto, podendo ser nova opção de consumo sustentável, se preocupa não só com as composições mais naturais em sua fórmula. Há, também, a valorização de questões éticas e sociais, além da extinção de testes em animais, por exemplo.

Além das questões éticas e ambientais, há diferentes fatores que levam à compra de cosméticos com viés sustentável. Embalagem, composição, saúde e beleza são alguns exemplos de aspectos a serem considerados na literatura estrangeira (Cervellon \& Carey, 2011; Ghazali, Soon, Mutum, \& Nguyen, 2017). Com essa constatação, esse trabalho visa 
responder a seguinte questão: "Quais os principais aspectos que os brasileiros consideram ao comprar cosméticos sustentáveis?"

O objetivo desta pesquisa foi identificar os principais aspectos considerados ao comprar cosméticos sustentáveis. A justificativa deste trabalho encontra-se pela fase embrionária na qual estão os estudos sobre a relação de fatores ambientais deste tipo de consumo e o comportamento do consumidor. Compreender quem estes consumidores de produtos sustentáveis são e indicar os fatores que determinam tal compra tem sido importante foco de estudos na área de marketing (Tamashiro, Silveira, Mantovani, \& Campanário, 2014). A lacuna que se pretende preencher é englobar os principais trabalhos sobre cosméticos sustentáveis e testá-los no contexto brasileiro.

Esta pesquisa apresenta as seguintes sessões após esta introdução: referencial teórico, explicitando a sustentabilidade nas organizações, cosméticos sustentáveis e fatores de compra; aspectos metodológicos; resultados e discussão; e considerações finais.

\section{Referencial Teórico}

\subsection{Sustentabilidade nas Organizações}

A sustentabilidade abrange as vertentes do tripé, conforme Elkington (2004): ambiental, social e econômico e a sustentabilidade é avaliada por números e indicadores. Quanto ao que rege o desenvolvimento sustentável, encontra-se a objetivação de crescer economicamente sem esquecer os lado ssocial e ambiental. Nessa proposta de desenvolvimento, busca-se um equilíbrio e se propõe, por meio de estratégias e práticas, uma mudança de comportamento para, a longo prazo, haver melhor qualidade de vida (bemestar) (Feil \& Schreiber, 2017).

Quanto aos aspectos econômicos do desenvolvimento sustentável, Amato Neto (2015) e Laasch e Conaway (2016) categorizam a sustentabilidade como fraca e forte. A sustentabilidade compreende somente o atendimento das necessidades empresariais e, posteriormente, a 
sustentabilidade, sem modificar estruturas, por exemplo; e a sustentabilidade forte que enxerga a necessidade de mudança disruptiva com estruturas existentes.

O que se tratava somente de imposição legal, redução de impacto ambiental, melhoria de imagem perante do consumidor e a sociedade (alguns dos stakeholders) e geração de lucro (Philippi, Sampaio, \& Fernandes, 2017), agora é uma parte integrante da tomada de decisão do consumidor. Assim, entra em cena a reformulação de negócios com princípios de sustentabilidade.

Os motivadores dessa reformulação podem ser necessidades dos stakeholders, novos mercados, convergência da crise global, internet e transparência, além de novos poderes institucionais. Laasch e Conaway (2016) expõem que, dentre os principais elementos pensados na definição de responsabilidade empresarial, temos o pensamento no stakeholder, seguido pelas dimensões social, econômica, assunção da responsabilidade voluntariamente e a dimensão ambiental em último lugar. Um dos fins de satisfazer os stakeholders é otimizar o valor a ele.

Como alguns dos pontos a satisfazer os consumidores, Fenker, Diehl, Alves, \& Kalinowski (2015) propõem a mudança da situação de risco de escassez de recursos e minimização da poluição, por meio da redução do consumo de recursos não-renováveis, tal como o petróleo e os seus derivados, além da utilização de mais recursos renováveis e mitigação de formas de degradação. Neste contexto, nota-se o mercado de cosméticos de viés sustentável como uma das saídas em busca de novos produtos que poluam menos e utilizem menos recursos não-renováveis.

\subsection{Cosméticos Sustentáveis e Fatores de Compra}

Os indivíduos prezam, nos cosméticos sustentáveis, não só a composição dos produtos, tais como os "ingredientes" ou as embalagens, mas também as questões sociais - melhoria das condições de trabalho, geração de emprego para a comunidade, capacitação de mão de obra são exemplos de 
valorização do capital humano inerentes às exigências sobre os produtos. Acerca das melhorias, o cosmético sustentável vem valorizar, também, os elementos naturais da região (Portal G1, 2019).

Para conceituar o que é um produto verde, compreendem-se certas características próprias: fabricados com matérias-primas renováveis ou recicláveis, ter embalagem leve, biodegradável e atender múltiplos propósitos (Tamashiro, Silveira, Mantovani, \& Campanário, 2014). Outra característica é não envolver mão de obra escrava em toda sua produção. Há também outra nomenclatura, Slow Beauty, que leva em consideração cosméticos naturais, veganos, utilizado com maior "consciência", sem teste em animais e orgânicos (Morais, 2019).

Quanto aos elementos explorados e com potencial de exportação pelo Brasil, existem diferentes óleos nacionais tais como o de buriti, o da castanha do Pará, além de manteiga de cupuaçu, manteiga da muru-muru e mel, por exemplo. Fonseca-Santos, Corrêa e Chorilli (2015) afirmam que este tipo de produto traz vantagens tais como usar materiais recicláveis, tornar o uso menos tóxico ao meio ambiente e à saúde. No Brasil, o Instituto Biodinâmico (IBD) (2014) traz as diretrizes para certificar produtos de beleza orgânicos e naturais e suas matérias-primas. Este instituto regulamenta normas para certificar cosméticos orgânicos. Algumas empresas convencionais no mercado brasileiro têm dedicado linhas inteiras de produtos com esta finalidade. Outras empresas oferecem opções mais naturais e possuem não só maquiagem e produtos para o cabelo, mas também creme dental e corporal.

Com esse maior interesse dos indivíduos em cosméticos sustentáveis, cabe às organizações prever suas vontades e as demandas do mercado. Predizer a intenção de compra pode ser compreendido como parte do estudo do comportamento do consumidor. Conforme demonstrado no Tabela 1, há diferentes aspectos na literatura que respondem à intenção de compra. 
Tabela 1. Fatores da intenção de compra de cosméticos sustentáveis

\begin{tabular}{|c|c|c|}
\hline Dimensões & Aspectos & Autores \\
\hline \multirow[b]{2}{*}{$\begin{array}{l}\text { Atitudes de } \\
\text { Consumo }\end{array}$} & Mudança de hábito & $\begin{array}{l}\text { Lages e Vargas Neto (2002); } \\
\text { Grohmann et al. (2012); Santos et } \\
\text { al. (2014) }\end{array}$ \\
\hline & $\begin{array}{c}\text { Consciência ecológica e } \\
\text { ética }\end{array}$ & $\begin{array}{l}\text { Ribeiro e Veiga (2011); Moser } \\
\text { (2015); Pudaruth, Juwaheer e } \\
\text { Seewoo (2015); Ghazali et al. } \\
\text { (2017) }\end{array}$ \\
\hline \multirow{2}{*}{ Bem-estar } & Vaidade & $\begin{array}{l}\text { Cervellon e Carey (2011); } \\
\text { Strehlau, Claro e Laban Neto } \\
(2014)\end{array}$ \\
\hline & Uso de cosméticos & $\begin{array}{l}\text { Strehlau, Claro e Laban Neto } \\
\text { (2014); Liobikiene e Bernatoniené } \\
\text { (2017) }\end{array}$ \\
\hline \multirow[t]{2}{*}{ Saúde } & Importância da saúde & $\begin{array}{l}\text { Lages e Vargas Neto (2002); } \\
\text { Cervellon e Carey (2011); } \\
\text { Grohmann et al. (2012); Tozzo, } \\
\text { Bertoncello e Bender (2012); Isaac } \\
\text { (2016); Ghazali et al. (2017) }\end{array}$ \\
\hline & Consciência da saúde & Michalidou e Hassan (2008) \\
\hline \multirow{3}{*}{$\begin{array}{l}\text { Grupos de } \\
\text { Referência }\end{array}$} & $\begin{array}{l}\text { Influência das mídias } \\
\text { sociais }\end{array}$ & $\begin{array}{l}\text { Sampaio (2012); Clarkson et al. } \\
\text { (2016); Medeiros et al. (2017) }\end{array}$ \\
\hline & $\begin{array}{l}\text { Influência do núcleo } \\
\text { familiar e amigos }\end{array}$ & $\begin{array}{l}\text { Kim e Chung (2011); Sampaio } \\
\text { (2012); Ghazali et al. (2017) }\end{array}$ \\
\hline & Influência de conhecidos & $\begin{array}{l}\text { Sampaio (2012); Ghazali et al. } \\
\text { (2017); Medeiros et al. }(2017)\end{array}$ \\
\hline \multirow{4}{*}{ Atributos percebidos } & Preço & $\begin{array}{l}\text { Santos et al. (2014); Ladeira, } \\
\text { Santini e Araújo (2015); Moser } \\
\text { (2015); Isaac (2016); Matić e Puh } \\
\text { (2016); Liobikiene e Bernatoniené } \\
\text { (2017); Singhal e Malik (2018) }\end{array}$ \\
\hline & $\begin{array}{l}\text { Conveniência e } \\
\text { disponibilidade }\end{array}$ & $\begin{array}{l}\text { Isaac (2016); Matić e Puh (2016); } \\
\text { Liobikiene e Bernatoniené (2017); } \\
\text { Singhal e Malik (2018) }\end{array}$ \\
\hline & Qualidade & $\begin{array}{l}\text { Ladeira, Santini e Araújo (2015); } \\
\text { Matić e Puh (2016) }\end{array}$ \\
\hline & Embalagem & $\begin{array}{l}\text { Bedante (2004); Ribeiro e Veiga } \\
\text { (2011); Tamashiro et al. (2014); } \\
\text { Ladeira, Santini e Araújo (2015); } \\
\text { Matić e Puh (2016); Singhal e } \\
\text { Malik (2018) }\end{array}$ \\
\hline
\end{tabular}

Fonte: Furtado e Sampaio (2018, p.6).

Em estudo sobre a compra de cosméticos sustentáveis, Furtado e Sampaio (2018) identificaram cinco fatores que podem influenciar a intenção de compra: atitude de consumo ambiental, bem-estar, saúde, grupos de referência e atributos percebidos. Com relação aos trabalhos sobre cosméticos sustentáveis e assuntos afins, foram identificados diferentes 
autores tratando sobre distintas dimensões. Posteriormente, cada trabalho foi analisado em conformidade com o seu conteúdo e sua relação com a temática desta pesquisa.

Na Tabela 2, apresentam-se os trabalhos e seus países de origem, assim como o objeto e os principais achados que condizem com o tema desta pesquisa, cosméticos sustentáveis.

Tabela 2. Resultado dos trabalhos do referencial

\begin{tabular}{|c|c|c|c|}
\hline Autor & $\begin{array}{l}\text { País da } \\
\text { pesquisa }\end{array}$ & Objeto de estudo & Relação \\
\hline $\begin{array}{l}\text { Bedante } \\
(2004)\end{array}$ & Brasil & $\begin{array}{l}\text { Intenção de compra de } \\
\text { produtos embalados } \\
\text { ecologicamente }\end{array}$ & $\begin{array}{l}\text { Positiva: Embalagens } \\
\text { importam ao comprar }\end{array}$ \\
\hline $\begin{array}{l}\text { Cervellon e } \\
\text { Carey (2011) }\end{array}$ & $\begin{array}{l}\text { Mônaco e } \\
\text { Canadá }\end{array}$ & $\begin{array}{l}\text { Consumo de cosméticos } \\
\text { verdes }\end{array}$ & $\begin{array}{l}\text { Negativa: Proteção ao } \\
\text { ambiente, identificação de } \\
\text { funcionalidade de cosméticos } \\
\text { naturais e benefícios da saúde }\end{array}$ \\
\hline $\begin{array}{l}\text { Clarkson et al. } \\
\quad \text { (2016) }\end{array}$ & Brasil & $\begin{array}{l}\text { Influência do marketing } \\
\text { digital nos cosméticos no } \\
\text { low poo }\end{array}$ & $\begin{array}{l}\text { Positiva: Mídias e qualidade } \\
\text { influenciam. } \\
\text { Negativa: preço não } \\
\text { influencia. }\end{array}$ \\
\hline $\begin{array}{l}\text { Ghazali et al. } \\
\quad \text { (2017) }\end{array}$ & Malásia & $\begin{array}{l}\text { Recompra de produto de } \\
\text { cuidado pessoal orgânico }\end{array}$ & $\begin{array}{l}\text { Positiva: preferência em } \\
\text { produtos verdes, preocupação } \\
\text { com ambiente e saúde. } \\
\text { Negativa: normas subjetivas } \\
\text { não influenciam. }\end{array}$ \\
\hline $\begin{array}{l}\text { Grohmann et } \\
\quad \text { al. (2012) }\end{array}$ & Brasil & $\begin{array}{l}\text { Validação da escala } \\
\text { ECCB no Brasil }\end{array}$ & $\begin{array}{l}\text { Positiva: preocupação com } \\
\text { ambiente, saúde na compra. } \\
\text { Preço, conveniência, qualidade } \\
\text { e embalagens influenciam. }\end{array}$ \\
\hline Isaac (2016) & Brasil & $\begin{array}{l}\text { Cosméticos orgânicos, } \\
\text { naturais e sustentáveis }\end{array}$ & $\begin{array}{l}\text { Positiva: preocupação com } \\
\text { saúde. Amigos, preço e } \\
\text { qualidade influenciam. } \\
\text { Negativa: ambiente não é } \\
\text { prioridade. Disponibilidade } \\
\text { não influencia. }\end{array}$ \\
\hline $\begin{array}{l}\text { Kim e Chung } \\
\text { (2011) }\end{array}$ & EUA & $\begin{array}{l}\text { Intenção de compra de } \\
\text { produtos de cuidado } \\
\text { pessoal orgânico }\end{array}$ & $\begin{array}{l}\text { Positiva: prioridade a } \\
\text { produtos verdes, preocupação } \\
\text { com aparência. Influência de } \\
\text { familiares e amigos na } \\
\text { decisão. }\end{array}$ \\
\hline $\begin{array}{c}\text { Ladeira, } \\
\text { Santini e } \\
\text { Araújo (2015) }\end{array}$ & Brasil & $\begin{array}{l}\text { EECB no consumo } \\
\text { consciente de cosméticos }\end{array}$ & $\begin{array}{l}\text { Positiva: preço e qualidade } \\
\text { influenciam ao comprar. }\end{array}$ \\
\hline $\begin{array}{c}\text { Lages e } \\
\text { Vargas Neto } \\
(2002)\end{array}$ & Brasil & $\begin{array}{l}\text { Consciência ecológica do } \\
\text { consumidor }\end{array}$ & $\begin{array}{l}\text { Positiva: preocupação com } \\
\text { ambiente e saúde influenciam. }\end{array}$ \\
\hline
\end{tabular}




\begin{tabular}{|c|c|c|c|}
\hline $\begin{array}{l}\text { Liobikiené e } \\
\text { Bernatoniené } \\
\text { (2017) }\end{array}$ & Lituânia & $\begin{array}{l}\text { Determinantes de } \\
\text { compra verde: caso de } \\
\text { cosméticos verdes }\end{array}$ & $\begin{array}{l}\text { Positiva: cosméticos auxiliam } \\
\text { consumidores, preocupação } \\
\text { com saúde. Preço, } \\
\text { conveniência e qualidade } \\
\text { influenciam. }\end{array}$ \\
\hline $\begin{array}{l}\text { Matić e Puh } \\
\quad(2016)\end{array}$ & Croácia & $\begin{array}{l}\text { Intenção de compra de } \\
\text { cosmético natural }\end{array}$ & $\begin{array}{l}\text { Negativa: há outros motivos } \\
\text { para comprar como segurança } \\
\text { e preocupação ética, não } \\
\text { saúde. }\end{array}$ \\
\hline $\begin{array}{l}\text { Medeiros et al. } \\
\text { (2017) }\end{array}$ & Brasil & $\begin{array}{l}\text { Intenção de compra de } \\
\text { produtos ecológicos }\end{array}$ & $\begin{array}{l}\text { Positiva: mídias e conhecidos } \\
\text { influenciam na compra. }\end{array}$ \\
\hline $\begin{array}{l}\text { Michaelidou e } \\
\text { Hassan (2008) }\end{array}$ & Escócia & $\begin{array}{l}\text { Saúde e segurança } \\
\text { alimentar perante } \\
\text { alimento orgânico }\end{array}$ & $\begin{array}{l}\text { Positiva: preferência a } \\
\text { produtos verdes. Preocupação } \\
\text { com saúde. } \\
\text { Negativa: há outros motivos } \\
\text { para comprar como segurança } \\
\text { e preocupação ética. }\end{array}$ \\
\hline Moser (2015) & Alemanha & $\begin{array}{c}\text { Antecedentes de compra } \\
\text { verde }\end{array}$ & $\begin{array}{l}\text { Positiva: preço, conveniência, } \\
\text { qualidade influenciam. Há } \\
\text { consciência ecológica ao } \\
\text { comprar. }\end{array}$ \\
\hline $\begin{array}{l}\text { Pudaruth, } \\
\text { Juwaheer e } \\
\text { Seewoo }\end{array}$ & $\begin{array}{l}\text { Ilhas } \\
\text { Maurício }\end{array}$ & $\begin{array}{l}\text { Compra de cosméticos } \\
\text { ecológicos e produtos de } \\
\text { beleza }\end{array}$ & $\begin{array}{l}\text { Positiva: há consciência } \\
\text { ecológica ao comprar. }\end{array}$ \\
\hline $\begin{array}{c}\text { Ribeiro e } \\
\text { Veiga (2011) }\end{array}$ & Brasil & $\begin{array}{l}\text { Proposição de escala de } \\
\text { consumo sustentável }\end{array}$ & $\begin{array}{l}\text { Positiva: há consciência } \\
\text { ecológica ao comprar. } \\
\text { Preocupação com embalagens } \\
\text { ao comprar. }\end{array}$ \\
\hline $\begin{array}{l}\text { Sampaio } \\
(2012)\end{array}$ & Brasil & $\begin{array}{l}\text { Intenção de compra de } \\
\text { alimentos orgânicos }\end{array}$ & $\begin{array}{l}\text { Positiva: Mídias, família e } \\
\text { conhecidos influenciam ao } \\
\text { comprar. }\end{array}$ \\
\hline $\begin{array}{l}\text { Santos et al. } \\
\quad(2014)\end{array}$ & Brasil & $\begin{array}{l}\text { Atitude e intenção de } \\
\text { compra de produto } \\
\text { sustentável }\end{array}$ & $\begin{array}{l}\text { Positiva: preocupação com } \\
\text { geração de prejuízos ao } \\
\text { ambiente, preço influencia. }\end{array}$ \\
\hline $\begin{array}{c}\text { Singhal e } \\
\text { Malik (2018) }\end{array}$ & Índia & $\begin{array}{l}\text { Questão social em } \\
\text { relação ao consumo de } \\
\text { cosméticos verdes }\end{array}$ & $\begin{array}{l}\text { Negativa: preço não influencia } \\
\text { na compra, assim como } \\
\text { disponibilidade e embalagens. }\end{array}$ \\
\hline $\begin{array}{l}\text { Strehlau, } \\
\text { Claro e Laban } \\
\text { Neto } \\
\end{array}$ & Brasil & $\begin{array}{c}\text { Vaidade e relação com } \\
\text { autoestima }\end{array}$ & $\begin{array}{l}\text { Positiva: preocupação com } \\
\text { aparência e uso de cosméticos } \\
\text { auxiliam os consumidores. }\end{array}$ \\
\hline $\begin{array}{l}\text { Tamashiro et } \\
\text { al. }(2014)\end{array}$ & Brasil & $\begin{array}{l}\text { Consumo de produtos } \\
\text { cosméticos verdes e } \\
\text { relação com preocupação } \\
\text { e afeto ecológico } \\
\end{array}$ & $\begin{array}{l}\text { Positiva: preocupação com } \\
\text { geração de prejuízos ao } \\
\text { ambiente, embalagem } \\
\text { influencia. }\end{array}$ \\
\hline $\begin{array}{c}\text { Tozzo, } \\
\text { Bertoncello e } \\
\text { Bender (2012) }\end{array}$ & Brasil & $\begin{array}{c}\text { Biocosméticos e } \\
\text { cosméticos orgânicos no } \\
\text { Brasil } \\
\end{array}$ & $\begin{array}{l}\text { Positiva: preocupação com } \\
\text { saúde influencia. }\end{array}$ \\
\hline
\end{tabular}

De acordo com a Teoria do Comportamento Planejado (TCP) de Ajzen (2018), três tipos de crença regem o comportamento: crença normativa (a respeito de outros, terceiros), crença comportamental (sobre algum 
comportamento) e crença de controle (fator que impede ou auxilia em um comportamento). A TCP considera ainda que os ambientes físico, social, valores, preconceitos e até mesmo exposição da informação afetam o comportamento (Ajzen, 2019). Observando a Figura 1, pode-se compreender as crenças e fatores que guiam o indivíduo.

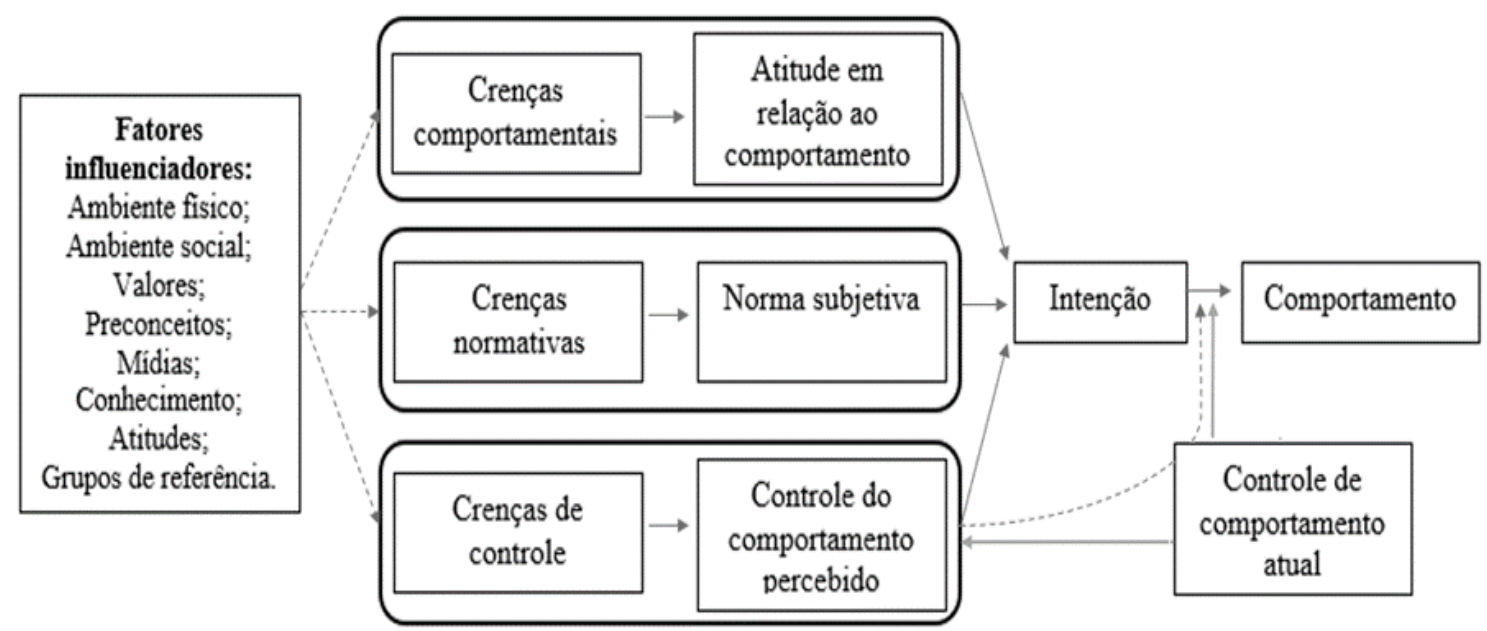

Figura 1. Diagrama da Teoria do Comportamento Planejado Fonte: Adaptado de Ajzen (2019).

Liobinkiené e Bernatoniené (2017), com seu estudo na Lituânia sobre categorias de determinantes de comportamento de compra verde, propõem um modelo baseado na teoria e na revisão bibliográfica. Fatores internos, tais como atitudes e valores, fatores sociais, pressão social e familiar, e fatores externos tais como preço, conveniência e qualidade são alguns exemplos de influenciadores.

Com a identificação de aspectos influenciadores na revisão bibliográfica, na teoria de Ajzen (2018) e com as categorias das autoras lituanas (Liobinkiené \& Bernatoniené, 2017), propõe-se um modelo teórico que relacione os dados e que explique os fatores acerca de cosméticos sustentáveis. Esse modelo guiará à construção do questionário a ser aplicado. 


\section{Aspectos Metodológicos}

Segundo Koller, Couto e Hohendorff (2014), sugere-se estudar temas que ainda não possuem total consenso entre autores e academia. Os trabalhos utilizados para embasar o referencial deste trabalho são, em sua maioria, 18 artigos e 3 dissertações. Há diferença entre a tipologia da coleta de dados nos trabalhos englobados no referencial, variando entre grupos focais, entrevistas e surveys, e há, também, diferentes grupos de fatores e grupos de variáveis estudados pelos autores.

Com o embasamento do referencial da Tabela 1, do diagrama de Ajzen (2018) e categorias de Liobinkiené e Bernatoniené (2017), houve a identificação de um modelo teórico com os fatores que influenciam a intenção de compra de cosméticos sustentáveis. Após essa proposição, foi elaborado um questionário aberto e, posteriormente, aplicado em consumidores de cosméticos sustentáveis.

A amostra foi não probabilística e por acessibilidade. Pela dificuldade em mapear um espaço físico em que se encontram consumidores deste tipo de produto, o contato foi realizado por grupos de redes sociais. O questionário possuía duas perguntas filtro: "Você é maior de 18 anos?" e “Comprou ou consumiu algum produto cosmético sustentável nos últimos 6 meses?". Ele foi aplicado em brasileiros via Google Forms, plataforma do Google de questionários online, em grupos do Facebook sobre no e low poo, transição capilar e cosméticos orgânicos a naturais, além do Instagram e Whatsapp.

A coleta ocorreu em agosto de 2018 e, após exclusão de erros de preenchimento, contou com a participação de 529 respondentes de 158 municípios, só não havendo respondentes nos estados do Acre, Amapá, Piauí e Roraima. As questões foram tratadas no site WordArt pela frequência.

\section{Resultados e Discussão}

Com a análise das teorias e do referencial, o modelo de fatores que orientam a intenção de compra de cosméticos sustentáveis englobou 3 
fatores: interno, externo e social, e 5 aspectos: Atitude de consumo ambiental, Bem-estar, Saúde, Grupos de Referência e Atributos percebidos (Figura 2).

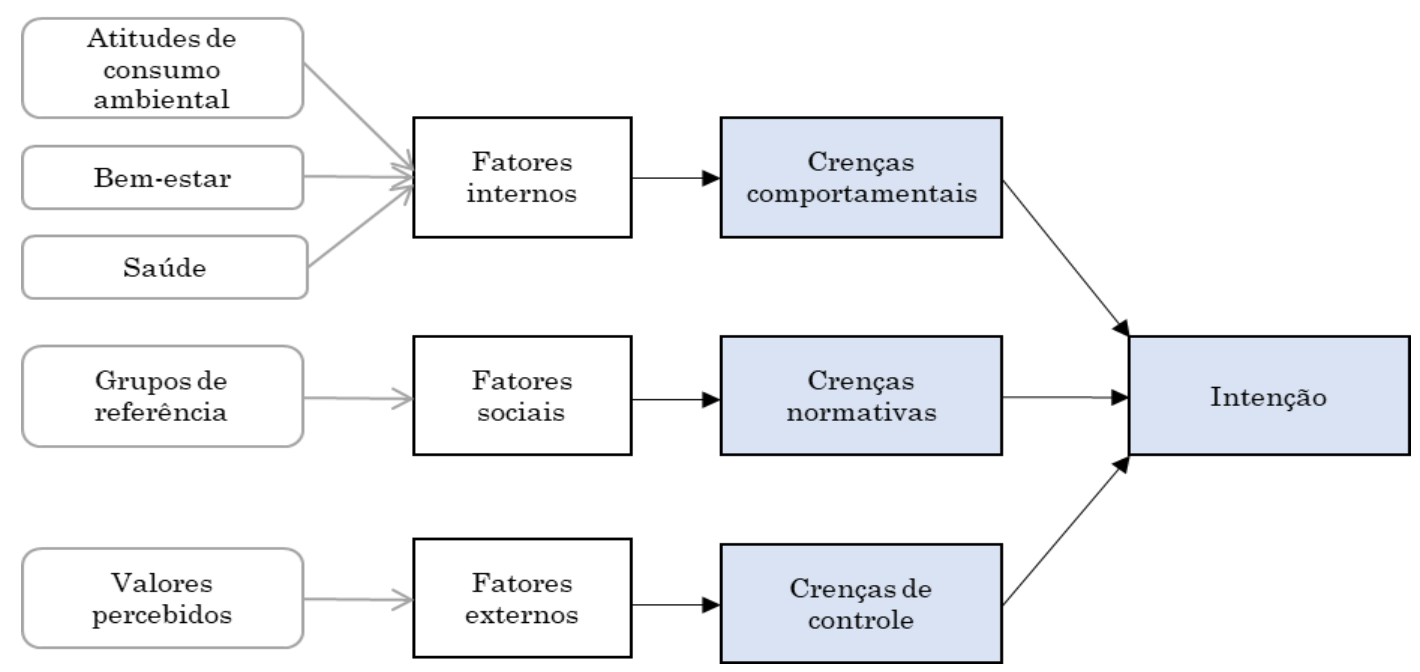

Figura 2. Modelo de intenção de compra

De acordo com as questões demográficas do questionário de pesquisa, o perfil dos consumidores é, em sua maioria, feminino (492 respondentes), com idades até 34 anos (413 respondentes). A maioria possui ensino superior (271 respondentes) e tem renda até dois salários mínimos (285 respondentes). A primeira pergunta do questionário de pesquisa foi "Qual a principal característica você valoriza ao comprar um cosmético sustentável?". Foram identificadas 95 palavras, com 840 repetições. Na Tabela 3, observam-se as 10 palavras mais citadas pelos respondentes, sendo qualidade a mais frequente. Outras características foram meio ambiente, preço, os ingredientes da composição e a embalagem.

A qualidade, palavra mais frequente, pode ser compreendida em diferentes aspectos. Desde desempenho, satisfação, aparência até experiência dos consumidores, que pode variar pela demanda de cada indivíduo. Solomon (2011) complementa que a qualidade pode ser uma comparação do indivíduo entre a expectativa e o desempenho acerca de um produto. A qualidade, o preço, a embalagem citados na questão 1 se 
encontram nos atributos percebidos do modelo (Tabela 1) e meio ambiente, teste em animais e saúde como fatores internos inerentes do indivíduo.

Tabela 3. 10 características mais frequentes

\begin{tabular}{ccc}
\hline Posição & Característica & Frequência \\
\hline $\mathbf{1}$ & Qualidade & 182 \\
2 & Meio Ambiente & 76 \\
3 & Teste em Animais & 66 \\
4 & Preço & 57 \\
5 & Procedência & 33 \\
6 & Natural & 30 \\
7 & Embalagem & 30 \\
8 & Saúde & 29 \\
9 & Vegano & 28 \\
10 & Ingrediente & 22 \\
\hline
\end{tabular}

A preocupação com o ambiente foi confirmada previamente (Ghazali et al., 2017; Grohmann et al., 2012; Lages \& Vargas Neto, 2002; Moser, 2015; Pudaruth, Juwaheer \& Seewoo, 2015; Ribeiro \& Veiga, 2011; Santos et al., 2014). A saúde foi também reafirmada neste trabalho como aspecto relevante para a compra de cosméticos sustentáveis (Cervellon \& Carey, 2011; Ghazali et al., 2017; Grohmann et al., 2012; Isaac, 2016; Lages \& Vargas Neto, 2002; Tozzo, Bertoncello \& Bender, 2012).

A segunda questão pesquisada foi "Qual marca deste tipo de cosmético você mais utiliza?". Extraíram-se 135 palavras e 796 repetições. As marcas mais frequentes foram Lola, Natura e Salon Line (Tabela 4). Das 10 marcas mais frequentes, todas são brasileiras. Nas outras palavras citadas, há marcas estrangeiras e convencionais no mercado tais como Tresemmé e Johnson, que já são produzidas no Brasil.

A terceira pergunta foi "Por que você optou por usar este tipo de produto?". De 1348 repetições, foram identificadas 270 palavras. As três mais frequentes foram qualidade, ambiente e saúde. As palavras animais, preço e pele são alguns motivos citados (Tabela 5). Dentre as respostas da 
pergunta, algumas podem ser destacadas como a do respondente 8 "Pelo lado sustentável: embalagens e esfoliantes que usam sementes no lugar de microplástico. Pela conveniência: preço é acessível e consigo encontrar com facilidade".

Tabela 4. 10 marcas mais frequentes

\begin{tabular}{ccc}
\hline Posição & Marcas & Frequência \\
\hline $\mathbf{1}$ & Lola & 138 \\
2 & Natura & 95 \\
3 & Salon Line & 54 \\
4 & Skala & 54 \\
5 & Boticário & 46 \\
6 & Yamasterol & 42 \\
7 & Granado & 41 \\
8 & Cativa Natureza & 25 \\
9 & Phebo & 18 \\
10 & Inoar & 16 \\
\hline
\end{tabular}

Tabela 5. 10 motivos mais frequentes

\begin{tabular}{ccc}
\hline Posição & Motivo de uso & Frequência \\
\hline $\mathbf{1}$ & Qualidade & 140 \\
2 & Ambiente & 93 \\
3 & Saúde & 68 \\
4 & Produto & 67 \\
5 & Animais & 59 \\
6 & Cabelo & 53 \\
7 & Preço & 36 \\
8 & Melhor & 35 \\
9 & Pele & 31 \\
10 & Resultado & 20 \\
\hline
\end{tabular}

Além da preocupação com o meio ambiente, a quantidade de respondentes atentando para a causa da crueldade e testes em cobaias é de 5\%. O respondente 15 sublinha: "Porque são livres de crueldade contra animais, e minha principal preocupação é com essa causa". O termo crueltyfree esteve presente nas respostas e é um dos achados de Pudaruth, 
Juwaheer e Seewoo (2015) como motivadores de compra de cosméticos sustentáveis.

Outra preocupação dos respondentes é com a saúde. Segundo o respondente 273 "Preocupação com o meu bem-estar e o bem-estar das pessoas à minha volta”. A saúde é um dos principais fatores de preocupação dos respondentes, e há respostas com informações de pesquisas (Rocha et al., 2018). Dados atuais de uso de cosméticos, além de possíveis encargos à saúde, demonstram que há conhecimento ou ao menos curiosidade dos consumidores sobre esse tipo de produto.

De acordo com o arcabouço teórico e com as perguntas do questionário, os fatores internos e externos possivelmente são os mais influenciadores na intenção de compra de cosméticos sustentáveis. Qualidade, meio ambiente, saúde, embalagem são alguns dos aspectos considerados pelos respondentes e confirmados na literatura.

\section{Considerações Finais}

Baseado no objetivo deste trabalho, identificar os principais aspectos que os brasileiros consideram ao comprar cosméticos sustentáveis, 5 aspectos foram encontrados na literatura e estão representados no modelo da Figura 2. Com os questionários, os fatores internos e externos prevaleceram como possivelmente mais relevantes na intenção de compra de consumidores. Aspectos inerentes a esses fatores foram identificados nos questionários tais como a qualidade, a embalagem, o meio ambiente, as aúde e o teste em animais.

Marcas brasileiras foram as mais citadas pelos respondentes do questionário. Denota-se marcas mais recentes no mercado como as mais relevantes, como Lola, Cativa Natureza e Inoar, enquanto marcas mais tradicionais têm criado linhas de produtos com viés sustentável, como Boticário, Yamasterol e Granado.

De acordo com os achados, os respondentes prezam a qualidade dos produtos que tenham viés sustentável, sem esquecer dos benefícios para sua 
saúde e a do meio ambiente. Um resultado que entra em consonância com estudos brasileiros (Tabela 1) é a preocupação com a embalagem. Os brasileiros têm tido maior interesse por cosméticos sustentáveis e têm motivações por trás do consumo, seja ele perante a eles mesmos ou ao vieses ambiental e social. O preço também teve seu lugar de destaque nos resultados, podendo ser um fator que, também, é considerado no momento da compra de cosméticos sustentáveis.

Dentre as contribuições deste trabalho, evidencia-se a relevância dos cosméticos com viés sustentável para os consumidores brasileiros deste segmento. Como implicação gerencial, as organizações, investindo em produção e estratégias de marketing para os consumidores, podem gerar valor a curto e a longo prazo. Além disso, as organizações podem gerar vantagens competitivas ao se preocuparem com a gestão do meio ambiente, não somente como greenwashing, que é o marketing ambiental realizado sem zelar de fato o ambiente, ou seja, de forma enganosa.

Quanto às contribuições acadêmicas, observam-se novos aspectos a serem estudados quanto a esse segmento de consumo: os atributos, a saúde e o meio ambiente. Esta pesquisa mostrou que esses aspectos estão presentes de forma uníssona como influenciadores de compra desse tipo de cosmético. Evidencia-se, então, uma sugestão de pesquisa futura, o aprofundamento nesses aspectos identificados como influenciadores.

Como limitação, evidencia-se o quantitativo das fontes de aplicação do questionário, sendo apenas online e por redes sociais. Além dessa limitação, apresenta-se a necessidade de recompartilhamentos e a demora do recebimento de respostas, por ser via internet. Como futuro passo dessa pesquisa, haverá aplicação de questionário com escalas validadas como forma de verificar os fatores empiricamente.

\section{Referências}

Ajzen, I. (2019). Selected Publications. Recuperado de https://people.umass.edu/aizen/tpb.background.html 
Amato Neto, J. (2007). A era do ecobusiness. Barueri: Manole.

Associação Brasileira da Indústria de Higiene Pessoal, Perfumaria e Cosméticos (2019) Do vegano ao sem perfume: indústria de cosméticos aposta em segmentação. Recuperado de https://abihpec.org.br/do-vegano-ao-semperfume-industria-de-cosmeticos-aposta-em-segmentacaol

Bedante, G. (2004). A influência da consciência ambiental e das atitudes em relação ao consumo sustentável na intenção de compra de produtos ecologicamente embalados. Dissertação de Mestrado, Universidade Federal do Rio Grande do Sul, Porto Alegre, RS.

Cervellon, M., \& Carey, L. (2011). Consumers'perceptions of 'green': Why and how consumers use eco-fashion and green beauty products. Critical Studies in Fashion and Beauty, 2(1-2), 117-138. https://doi.org/10.1386/csfb.2.1-2.117 1

Clarkson, C., Queiroz, R. C., Soares, G. M., \& Ribeiro, P. C. (2016, outubro). Avaliação da influência do marketing digital no setor de cosméticos: técnica no/low poo. Anais do Encontro Fluminense de Engenharia de Produção, Enfepro, Niterói, RJ, Brasil, 6.

Dias, R. (2015). Sustentabilidade. São Paulo: Atlas.

Elkington, J. (2004). Enter the triple bottom line. In: A. Henriques \& J. Richardson (Eds.). The triple bottom line, does it all add up? (pp. 1-16). London: Earthscan Publications Ltd.

Feil, A. A. \& Schreiber, D. (2017) Sustentabilidade e desenvolvimento sustentável: desvendando as sobreposições e alcances de seus significados. Caderno EBAPE.BR, 14(3), 667-681. https://doi.org/10.1590/1679-395157473

Fenker, E. A., Diehl. C. A., Alves, T. W., \& Kalinowski C. (2015). Gestão ambiental. São Paulo: Atlas.

Fonseca-Santos, B., Côrrea, M. A., \& Chorilli, M. (2015). Sustainability, natural and organic cosmetics: consumer, products, efficacy, toxicological and regulatory considerations. Brazilian Journal of Pharmaceutical Sciences, 51(1), 17-26. https://doi.org/10.1590/S1984-82502015000100002

Furtado, B. A., \& Sampaio, D. O. (2018, novembro). Fatores que influenciam a intenção de compra de cosméticos sustentáveis: proposta de um modelo teórico. Anais dos Seminários em Administração da Universidade de São Paulo, Semead, São Paulo, SP, Brasil, 21.

Ghazali, E., Soon, P. C., Mutum, D., \& Nguyen, B. (2017). Health and cosmetics: Investigating consumers' values for buying organic personal care 
products. Journal of Retailing and Consumer Services, 39, 154-163. https://doi.org/10.1016/j.jretconser.2017.08.002

Gollo, S., Silva, A., Locatelli, D., \& Rangel, A. C. (2015, setembro). Comportamento do Consumidor no Processo de Compra e Consumo de Produtos Sustentáveis. Anais do Congresso Internacional de Administração, Universidade Estadual de Ponta Grossa, Ponta Grossa, PR, Brasil, 12.

Grohmann, M., Battistella, L., Velter, A., \& Casasola, F. (2012). Comportamento ecologicamente consciente do consumidor: adaptação da escala ECCB para o contexto brasileiro. Revista de Gestão Social e Ambiental (RGSA), 6(1), 102-116. https://doi.org/10.24857/rgsa.v6i1.321

Instituto Biodinâmico (2014). Diretrizes para certificação de produtos de saúde e beleza orgânicos e naturais. Botucatu, SP: IBD Certificações. Recuperado de https:/www.ibd.com.br/wp-content/uploads/2019/09/8 12 Diretrizes IBD Cosmeticos 5aEd 082014 V.pdf.

Isaac, G. E. A. (2016). O desenvolvimento sustentável do setor cosmético e o comportamento do consumidor frente aos cosméticos sustentáveis. Dissertação de mestrado, Centro Universitário das Faculdades Associadas de Ensino, São João da Boa Vista, SP, Brasil.

Estadão. (2018, janeiro 29). A beleza da sustentabilidade: indústria de cosméticos se reformula para produzir de maneira mais verde. Recuperado de http://economia.estadao.com.br/blogs/ecoando/a-beleza-dasustentabilidade-industria-de-cosmeticos-se-reformula-para-produzir-demaneira-mais-verde/

Kim, H. Y., \& Chung, J. (2011). Consumer purchase intention for organic personal care products. Journal of Consumer Marketing, 28(1), p. 40-47. https://doi.org/10.1108/07363761111101930

Kotler, P., \& Keller, K. (2012). Administração de Marketing. São Paulo: Pearson Education do Brasil.

Laasch, O., \& Conaway, R. (2016). Fundamentos da gestão responsável. Cengage Learning: São Paulo.

Ladeira, W., Santini, F., \& Araújo, C. (2015). Aplicabilidade da Escala ECCB ao Paradigma da Modelagem de Segunda Ordem: uma análise do consumo consciente de cosméticos. Revista de Administração, Contabilidade e Economia (RACE), 14(2), 451-478. https://doi.org/10.18593/race.v14i2.5830

Lages, N., \& Vargas Neto, A. (2002, setembro). Mensurando a consciência ecológica do consumidor: um estudo realizado na cidade de Porto Alegre. 
Anais do Encontro da Associação Nacional de Pós-Graduação e Pesquisa em Administração (EnANPAD), Salvador, BA, 26.

Liobikiené, G., \& Bernatoniené, J. (2017). Why determinantes of green purchase cannot be treated equally? The case of green cosmetics: Literature review. Journal of Cleaner Production, 162, 109-120. https://doi.org/10.1016/j.jclepro.2017.05.204

Matić, M., \& Puh, B. (2016). Consumers'purchase intentions towards natural cosmetics. Review of Contemporary Business, Entrepreneurship and Economic Issues (Econviews), 29(1), 53-64.

Medeiros, H., Studart, L. B. A., Souza, L., \& Moura, H. J. (2017). Influências das mídias sociais na intenção de compra de produtos verdes. Caderno Profissional de Marketing, UNIMEP, 5(3), 89-102.

Michaelidou, N., \& Hassan, L. (2008). The Role of Health Consciousness, Food Safety Concern and Ethical Identity on Attitudes and Intentions towards Organic Food. International Journal of Consumer Studies, 32(2), 163-170. https://doi.org/10.1111/j.1470-6431.2007.00619.x

Morais, I. C. (2019). Re-enchantment of consumption through craft products: An analysis of the homemade cosmetics context. Tese de Doutorado, Universidade de São Paulo, São Paulo, SP, Brasil.

Moser, A. (2015). Thinking green, buying green? Drivers of proenvironmental purchasing behavior. Journal of Consumer Marketing, 32(3), 167-175. https://doi.org/10.1108/JCM-10-2014-1179

Philippi, A., Sampaio, C. A., \& Fernandes, V. (2017). Gestão empresarial e sustentabilidade. Barueri: Manole.

Portal G1 (2019, janeiro 7). Cosméticos sustentáveis: conheça os desafios dessa indústria para diminuir impactos ambientais. Recuperado de https://g1.globo.com/sc/santa-catarina/especial-publicitario/falando-desustentabilidade/noticia/2019/01/07/cosmeticos-sustentaveis-conheca-osdesafios-dessa-industria-para-diminuir-os-impactos-ambientes.ghtml

Pudaruth, S., Juwaheer, T., \& Seewoo, Y. (2015). Gender-based differences in understanding the purchasing patterns of eco-friendly cosmetics and beauty care products in Mauritius: a study of female costumers. Social Responsibility Journal, 11(1), p. 179-198. https://doi.org/10.1108/SRJ-042013-0049

Ribeiro, J., \& Veiga, R. (2011). Proposição de uma escala de consumo sustentável. Revista de Administração, 46(1), 45-60. https://doi.org/10.5700/rausp0997 
Rocha, B. A et al. (2018). Advanced data mining approaches in the assessment of urinary concentrations of bisphenols, chlorophenols, parabens and benzophenones in Brazilian children and their association to DNA damage. Environment International, 116, 269-277. https://doi.org/10.1016/j.envint.2018.04.023

Sampaio, D. (2013). Intenção de compra e consumo de alimentos orgânicos: um estudo sobre as crenças, atributos e grupos de referência. Tese de Doutorado, Universidade Federal de Minas Gerais, Belo Horizonte, MG, Brasil.

Santos, J., Ferreira, M. C. O., Bizarrias, F. S., \& Silva, J. G. (2014, dezembro). Atitude e intenção na compra de produto sustentável. Anais do Encontro Internacional sobre Gestão e Meio Ambiente (ENGEMA), São Paulo, SP, Brasil, 16.

Singhal, A., \& Malik, G. (2018) The attitude and purchasing of female consumers towards green marketing related to cosmetic industry. Journal of Science and Technology Policy Management, ahead-of-print. https://doi.org/10.1108/JSTPM-11-2017-0063

Solomon, M. (2011). O comportamento do consumidor. Porto Alegre: Bookman.

Strehlau, V. I., Claro, D., \& Laban, S. (2015). A vaidade impulsiona o consumo de cosméticos e de procedimentos estéticos cirúrgicos nas mulheres? Uma investigação exploratória. Revista de Administração, 50(1), 73-88. https://doi.org/10.5700/rausp1185

Tamashiro, H. R. S., Silveira, J. A. G., Mantovani, D. M. N., \& Campanário, C. R. A. A. (2014). Aspectos determinantes do consumo de produtos cosméticos verdes. Revista de Administração e Inovação, 11(1), 238-262. https://doi.org/10.5773/rai.v11i1.1206

Tozzo, M., Bertoncello, L., \& Bender, S. (2012). Biocosmético ou cosmético orgânico: revisão de literatura. Revista Thêma et Scientia, 2(1), 122-130.

Zenone, L. C., \& Dias, R. (2015). Marketing sustentável. São Paulo: Atlas. 